\title{
ORIGINAL ARTICLE Hormonal, metabolic and nutritional alterations in smokers: emergency for smoking abstinence
}

\author{
Alterações metabólicas, hormonais e nutricionais de \\ fumantes: urgência para a abstinência tabágica \\ Gláucia Renata Souza Rodrigues', Marcela Melquíades', Maria Alvim Leite², Maíra Barros Louro², \\ Carmen Perches ${ }^{3}$, Ana Lúcia de Almeida Vargas ${ }^{4}$, Sheila Cristina Potente Dutra Luquetti ${ }^{1,5}$, \\ Aline Silva de Aguiar Nemer ${ }^{1,5,6}$
}

\section{Keywords}

Smoking, cardiovascular diseases, dyslipidemia, overweight.

\begin{abstract}
Objective: To evaluate the biochemical and nutritional status of smokers in treatment for smoking cessation and its association with anthropometric parameters. Methods: This is a cross-sectional study with convenience sample. Adult smokers were assessed at the start of treatment in the Interdisciplinary Center for Tobacco Research and Intervention of the University Hospital of the Federal University of Juiz de Fora (CIPIT/HU-UFJF). We evaluated the body mass index (BMI), conicity index (Cl); waist circumference (WC), percentage of body fat (\%BF), fasting glycemia, cortisol, insulin, total cholesterol (TC), LDL-C, HDL-C, triglycerides (TG) and metabolic syndrome (MS). Results: Most participants (52.2\%) had MS and high cardiovascular risk. The fasting glycemia was abnormal in $30.4 \%$. There was a significant positive correlation between BMI and WC ( $r=0.90 ; p=0.0001)$, $B F(r=0.79 ; p=0.0001), C l(r=0.65 ; p=0.0001)$, glycemia $(r=0.42 ; p=0.04)$ and TG $(r=0.47 ; p=0.002)$. The $C l$ presented positive correction with insulin ( $r=0.60 ; p=0.001)$, glycemia $(r=0.55 ; p=0.007), T G(r=0.54 ; p=0.008)$ and \%BF $(r$ $=0.43 ; p=0.004)$. Patients with longer duration of smoking had a higher risk of developing MS $(\mathrm{OR}=9.6, \mathrm{p}=0.016)$. Conclusion: The smokers evaluated had increased risk for developing MS, especially those with longer duration of smoking, requiring urgent smoking cessation.
\end{abstract}

\section{RESUMO}

Objetivo: Avaliar o perfil bioquímico e nutricional de fumantes em tratamento para a cessação tabágica e sua associação com parâmetros antropométricos. Métodos: Trata-se de um estudo transversal com amostra de conveniência. Adultos fumantes foram avaliados no início do tratamento no Centro Interdisciplinar de Pesquisa e Intervenção em Tabagismo do Hospital Universitário da Universidade Federal de Juiz de Fora (CIPIT/HU-UFJF). Foram avaliados o índice de massa corporal (IMC), índice de conicidade (IC), circunferência da cintura (CC), percentual de gordura corporal (\%GC), glicemia de jejum, cortisol, insulina, colesterol total (TC),

\footnotetext{
1 Universidade Federal de Juiz de Fora, Hospital Universitário (UFJF/HU), Residência Multiprofissional em Saúde do Adulto, Juiz de Fora, MG, Brazil.

2 Instituto de Ciências Biológicas, Departamento de Nutrição, Iniciação Científica do Curso de Nutrição, UFJF, Juiz de Fora, MG, Brazil. 3 UFJF/HU, Laboratório de Análises Clínicas, Juiz de Fora, MG, Brazil.

4 UFJF/HU, Centro Interdisciplinar de Pesquisa e Intervenção em Tabagismo (CIPIT), Juiz de Fora, MG, Brazil.

5 UFJF, Instituto de Ciências Biológicas, Departamento de Nutrição, Juiz de Fora, MG, Brazil.

6 Universidade Federal de Ouro Preto (UFOP), Programa de Mestrado em Saúde e Nutrição, Ouro Preto, MG, Brazil.
}

Correspondence address to: Aline Silva de Aguiar Nemer

Universidade Federal de Juiz de Fora, Instituto de Ciências Biológicas,

Departamento de Nutrição, Cidade Universitária

36036-900 - Juiz de Fora, MG, Brazil

Telephone: (+ 55 32) 2102-3234

E-mail: aline.nemer@uff.edu.br 


\author{
Palavras-chave \\ Tabagismo, doenças \\ cardiovasculares, \\ dislipidemias, sobrepeso.
}

colesterol LDL-c, HDL-c, triglicéridos (TG) e síndrome metabólica (SM). Resultados: A maioria dos participantes possuía SM e alto risco cardiovascular. A glicemia de jejum estava alterada em 30,4\%. Houve correlação positiva significativa entre IMC e CC ( $r=0,90 ; p=0,0001)$, \%GC $(r=0,79 ; p=0,0001), I C(r=0,65 ; p=0,0001)$, glicemia $(r=0,42 ; p=0,04)$ e TG $(r=0,47 ; p=$ $0,002)$. O IC também apresentou correlação positiva com insulina ( $r=0,6 ; p=0,001)$, glicemia $(r=0,55 ; p=0,007)$, TG $(r=0,54 ; p=0,008)$ e $\% G C(r=0,43 ; p=0,004)$. Pacientes com maior tempo de tabagismo tiveram maior risco de desenvolver $S M(O=9,6 ; p=0,016)$. Conclusão: Os fumantes avaliados tiveram maior risco de desenvolver SM, especialmente aqueles que fumavam por mais tempo, requerendo urgência para a cessação tabágica.

\section{INTRODUCTION}

Smoking represents one of the main modifiable risk factors for chronic diseases such as cardiovascular diseases, diabetes mellitus and cancer, is considered the most important public health problem in the present ${ }^{1}$. The World Health Organization (WHO) estimates that 1.2 billion people are smokers and that this number could rise to 1.6 billion in 2030. Total deaths worldwide, caused by smoking, are about 5 million a year. In Brazil are estimated about 200000 deaths/year as a result of tobacco dependence ${ }^{2}$. According to the Surveillance System Risk and Protective Factors for Chronic Diseases Survey Telephone (VIGITEL), smoking prevalence among the adult population of the 27 Brazilian capitals was 14.8\%, higher in men (18.1\%) than in women (12.0\%)

The cigarette consists of approximately 4,720 toxic substances ${ }^{4}$, and nicotine the main substance responsible for tobacco dependence and the development of chronic diseases, particularly cardiovascular disease ${ }^{5}$. Each cigarette contains an average of 7-9 mg of nicotine, of which it is estimated that slightly more than $1 \mathrm{mg}$ to be absorbed by the smoker".

Cigarette smoking acts at various levels in the pathogenesis of chronic diseases, among them the metabolic syndrome (MS) and cardiovascular disease ${ }^{6}$. Risk factors of metabolic origin have been described to explain its harmful effects on the cardiovascular system, such as hypertension, decreased plasma levels of HDL-cholesterol (HDL-C), hypertriglyceridemia, impaired fasting glucose and abdominal obesity ${ }^{7}$. According to the Institute of Diabetes Federation? the presence of increased abdominal fat, two risk factors listed above characterize the MS and are able to increase the overall mortality by 1.5 times and cardiovascular diseases 2.5fold 5,9 .

Endocrine disorders can also be present in smokers and corroborate, directly or indirectly to the development of comorbidities related to tobacco use. Studies have shown increased plasma levels of cortisol, especially in the first hour after smoking ${ }^{10,11}$. The increase of this hormone is associated with changes in body composition and increased visceral fat mass, which in turn has an increased number of receptors for cortisol ${ }^{12,13}$. In addition, chronic smokers are at increased risk for developing insulin resistance and inadequate compensatory response of insulin secretion, which promotes the association of smoking with an increased risk of type 2 diabetes mellitus ${ }^{14}$.

Evaluation of endocrine-metabolic changes that promote tobacco use, can aid understanding of factors involved in the changes of body weight and the development of chronic diseases associated with smoking. This article aims to evaluate the biochemical and nutritional status of smokers at the start of treatment for smoking cessation and its association with anthropometric indices.

\section{METHODS}

This is a cross-sectional study with convenience sampling conducted in smokers treated in the second half of 2011 by the Interdisciplinary Center for Tobacco Research and Intervention of the University Hospital of the Federal University of Juiz de Fora (CIPIT/HU-UFJF). We evaluated individuals of both sexes, aged between 19 and 59 years who agreed to participate and signed the Free and Clarified Consent Term. Enrollment for the study was voluntary. Pregnant women, nursing mothers and patients with severe psychiatric disorder and diseases that interfere with nutritional and metabolic status (infectious, kidney, cardiac, endocrine or liver diseases) were excluded. Pregnant women, breastfeeding women and patients with severe psychiatric disorders and diseases that interfere with the nutritional and metabolic (infectious, renal, cardiac, endocrine or liver disease) were excluded. All patients enrolled by CIPIT/HU-UFJF the second half of 2011 were invited to participate in the study. However, only 30 smokers effectively started treatment, but only 23 were included in this study because of the exclusion criteria. The proposal was approved by the Ethics in Research Committee of the University Hospital from UFJF (CAAE: 0067.180.420-11).

In the first day of follow-up, clinical history and anthropometric measurements and the degree of nicotine dependence were assessed in each of the smokers for trained professionals and students working on the ambulatory. 
Clinical histories were collected type information duration of smoking, age at initiation of smoking, number of cigarettes smoked per day, among others. Was used the Fagerström Nicotine Dependence Test (FNDT) to measure the degree of nicotine dependence ${ }^{15,16}$. The questionnaire has six questions that are intended to identify the smokers' behavior, and for each question there is a corresponding score. The total score obtained in the six responses resulted in a score that indicates the degree of dependence: low (0-4 points), moderate (5 points) or high (5-10 points).

Anthropometric nutritional assessment was performed at the beginning of the treatment. Body weight (BW), height, waist circumference (WC) and abdominal circumference (AC) were measured in private rooms and with standardized protocols ${ }^{17}$. The BW measurement was performed using electronic digital balance (Welmy ${ }^{\circledast}$ ), and the patient was evaluated shoeless and wearing light clothing. Height was measured using a stadiometer attached to a balance with the patient standing, barefoot, with arms outstretched to the sides and heels together, erect head with eyes fixed on the horizon, touching the vertical rod of the stadiometer.

To assess the nutritional status, body mass index (BMI) was calculated by the formula: $\mathrm{BMI}=$ weight $(\mathrm{kg}) /$ height $\left(\mathrm{m}^{2}\right)$. The classification was performed as proposed by ${ }^{17}$, for adults, or Lipschitz ${ }^{18}$, for the elderly patients. The percentage of body fat (\%BF) was estimated by BMI, using the following formulas: Men [\%fat = $1.218(\mathrm{BMI})-10.13$ ] and women [\%fat $=1.48(\mathrm{BMI})-7]^{19}$. The values obtained were classified according to the proposed by Lohman $(1991)^{20}$.

WC was made with a flexible and inextensible measuring tape, with the individual standing, identified the midpoint between the last rib and the iliac crest, in the natural curvature. From this point was measured the circumference and the reading of the measurement was made at the time of expiration ${ }^{17}$. The interpretation of the results followed the cutoffs $W C \geq 90 \mathrm{~cm}$ for men and $W C \geq 80 \mathrm{~cm}$ for women, indicating risk of cardiovascular disease measures that exceeded these values. AC was measured using flexible and inextensible measuring tape encircling the abdomen at the umbilicus scar. The conicity index was calculated using the equation: $\mathrm{Cl}$ = waist circumference $(\mathrm{m}) /[0.109 \times(\sqrt{ } \mathrm{P}(\mathrm{kg}) /$ $E(m)]$ according to the protocol proposed by Valdez $z^{21}$. This measure assesses the presence of cardiovascular risk from the high cutoff points 1.25 and 1.18 for men and women, respectively ${ }^{22}$.

The Laboratory assessments were performed after the participants had fasted overnight, blood samples were drawn to measure serum total cholesterol (TC), HDL cholesterol (HDL-C), triacylglycerols (TG), and plasma glucose, insulin and cortisol. These tests were performed at the Laboratory of Clinical Analyses of University Hospital of Federal University of Juiz de Fora, using specific kits available in the laboratory. Glucose tolerance was estimated using the resistance index Homeostasis Model Assessment (HOMA-IR) calculated by measuring fasting blood glucose and insulin, according to the following formula: [glucose ( $\mathrm{mmol} / \mathrm{L}$ )xinsulin $(\mathrm{U} / \mathrm{mL}) / 22.5]^{23}$. Insulin resistance was classified individuals who had HOMA-IR $>4.65^{24}$.

Blood pressure was measured with the patient seated after 5 minutes of rest, according to standard procedures, being classified as high blood pressure $\geq 130 / 85 \mathrm{mmHg}^{25}$.

For all participants, the adult IDF definition of the metabolic syndrome was applied ${ }^{26}$. According to the IDF ${ }^{8}$ definition, an individual has the metabolic syndrome if he or she has central adiposity plus at least two of the following criteria: 1) triglycerides $\geq 150 \mathrm{mg} / \mathrm{dL}, 2$ ) HDL cholesterol $<40$ $\mathrm{mg} / \mathrm{dL}$, 3) systolic blood pressure $\geq 130 \mathrm{mmHg}$ or diastolic blood pressure $\geq 85 \mathrm{mmHg}$, 4) fasting plasma glucose $\geq 100$ $\mathrm{mg} / \mathrm{dL}$ or previously diagnosed type 2 diabetes.

\section{Statistical analysis}

Statistical analysis was performed using Epi-Info 6.0 and SPSS 12.0. First, we conducted a descriptive analysis of the measured parameters (nutritional status and biochemical tests), using mean, standard deviation and maximum and minimum values of proportion, as the variable type to be described. After analysis of the data normality by the Shapiro-Wilk comparisons of continuous variables of anthropometry and biochemical tests were conducted by nonparametric test (Mann-Whitney $U$ test). Categorical variables were compared by chi-square. The association between hormone levels and the variables of interest was verified by Spearman correlation. We used logistic regression to assess the risk of developing MS compared to the duration of smoking. In all analyzes was considered the significance level of 0.05 .

\section{RESULTS}

The study involved 23 smokers at the start of treatment. Of these, the majority were women $(73.9 \%)$, with a mean age of $43.7 \pm 11$ years. Of all individuals, $82.6 \%$ started smoking before adulthood, $69.6 \%$ were light smokers, $26.1 \%$ moderate smokers and $4.3 \%$ heavy smokers. The degree of nicotine dependence, as measured by the FTND, appeared high in $65.2 \%$ of subjects (Table 1 ).

The mean BMl was $28.28 \pm 6.46 \mathrm{~kg} / \mathrm{m}^{2}$, of which $65.2 \%$ were overweight (overweight $n=7 /$ obesity $n=8$ ) and $82.6 \%$ central obesity from the measurement of WC. The presence of MS was seen in 52.2\% patients. The IC was used as a discriminator for high cardiovascular risk and this was found in $52.2 \%$ of individuals, and of these, $75 \%$ also had MS.

The mean values of cardiovascular and metabolic parameters at the beginning of treatment for smoking cessation 
are shown in table 2. Among the characteristics of smokers can observe that the \%BF was increased in $69.6 \%$ of subjects, serum concentrations of TC and LDL-c levels were elevated, respectively $52.2 \%$ and $78.3 \%$ individuals. The $\mathrm{HDL}-\mathrm{c}$ was below the recommended values in $65.2 \%$ of patients. Hypertriglyceridemia was observed in $39.1 \%$ subjects. It was found impaired fasting glucose $30.4 \%$ while $8.7 \%$ of patients had glucose levels compatible with diabetes ( $\geq 126 \mathrm{mg} / \mathrm{dL}$ ). Only one individual (4.3\%) had serum cortisol and insulin above the reference values. The presence of impaired glucose tolerance, assessed by HOMA-IR was found in 13\% of participants. Although the mean values of systolic and diastolic be within the reference values, $30.4 \%$ of subjects had increased blood pressure.

There was no association between the number of cigarettes/day and the degree of nicotine dependence with hormone levels, metabolic and anthropometric parameters. However, patients with longer duration of smoking had a higher odds of developing MS (OR = 9.6, $p=0.016$ ) (Table 3). There was a positive correlation between $\mathrm{BMI}$ and $\mathrm{WC}(\mathrm{r}$ $=0.90 ; p=0.0001)$, \%BF $(r=0.79 ; p=0.0001), C l(r=0.65 ; p$ $=0.0001)$, glycemia $(r=0.42 ; p=0.04)$ and $T G(r=0.47 ; p=$ $0.002)$. The $\mathrm{Cl}$ presented positive correction with insulin ( $r=$ $0.60 ; p=0.001)$, glycemia $(r=0.55 ; p=0.007), \mathrm{TG}(r=0.54 ; p=$ $0.008)$ and $\% B F(r=0.43 ; p=0.004)$. There was also a positive correlation between insulin and WC $(r=0.74 ; p=0.001)$ and $\mathrm{Cl}(r=0.60 ; p=0.001)$ (Table 4).

Table 1. Characteristics of smoking at the beginning of treatment for smoking cessation

\begin{tabular}{|c|c|c|}
\hline Variables & n & $\%$ \\
\hline \multicolumn{3}{|l|}{ Age of onset of smoking } \\
\hline 9 a 19 years & 19 & 82.6 \\
\hline 20 a 39 years & 4 & 17.4 \\
\hline$>40$ years & 0 & 0.0 \\
\hline Total & 23 & 100.0 \\
\hline \multicolumn{3}{|l|}{ Number of cigarettes smoked per day } \\
\hline 1-20 (Light consumption) & 16 & 69.6 \\
\hline 21-40 (Moderate consumption) & 6 & 26.1 \\
\hline > 41 (Heavy consumption) & 1 & 4.3 \\
\hline Total & 23 & 100.0 \\
\hline \multicolumn{3}{|l|}{ Duration of smoking } \\
\hline$\leq 10$ years & 3 & 13.0 \\
\hline$>10$ years & 20 & 87.0 \\
\hline Total & 23 & 100.0 \\
\hline \multicolumn{3}{|l|}{ Degree of dependence } \\
\hline Low & 3 & 13.1 \\
\hline Moderate & 5 & 21.7 \\
\hline High & 15 & 65.2 \\
\hline Total & 23 & 100.0 \\
\hline
\end{tabular}

Table 2. Cardiovascular and metabolic parameters at the beginning of treatment for smoking cessation

\begin{tabular}{|c|c|c|c|}
\hline Variables & Mean $\pm D P$ & $\begin{array}{l}\text { Minimum- } \\
\text { Maximum }\end{array}$ & Reference value \\
\hline \multicolumn{4}{|l|}{ Blood pressure $(\mathrm{mmHg})$} \\
\hline Systolic & $126.87 \pm 19.14$ & $100-170$ & $<130$ \\
\hline Diastolic & $81.70 \pm 10.13$ & $62-100$ & $<85$ \\
\hline \multicolumn{4}{|l|}{ Waist circumference (WC-cm) } \\
\hline Men & $90.83 \pm 11.46$ & $85-105$ & $<90$ \\
\hline Women & $87.91 \pm 14.40$ & $68-120$ & $<80$ \\
\hline \multicolumn{4}{|l|}{ Conicity index (Cl) } \\
\hline Men & $1.20 \pm 0,07$ & $1.12-1.32$ & $<1.25$ \\
\hline Women & $1.19 \pm 0,07$ & $1.10-1.31$ & $<1.18$ \\
\hline \multicolumn{4}{|l|}{$\%$ Body Fat (\%BF) } \\
\hline Men & $31.46 \pm 11.38$ & $14.11-28.46$ & $<15$ \\
\hline Women & $35.51 \pm 10.57$ & $20.68-60.84$ & $<23$ \\
\hline \multicolumn{4}{|l|}{ Lipid profile (mg/dL) } \\
\hline TC & $201.70 \pm 49.02$ & $84-274$ & $<200$ \\
\hline HDL-C & $45.04 \pm 7.47$ & $31-63$ & $\begin{array}{c}\geq 40 \text { men } \geq 50 \\
\text { women }\end{array}$ \\
\hline LDL-C & $129.30 \pm 40.82$ & $30-199$ & $<100$ \\
\hline TG & $137.04 \pm 69.62$ & $46-260$ & $<150$ \\
\hline Fasting plasma glucose (mg/dL) & $98.17 \pm 16.10$ & $75-140$ & $<127$ \\
\hline HOMA-IR & $2.26 \pm 1.80$ & $0.66-8.00$ & $\leq 4.65$ \\
\hline Insulin (mclU/mL) & $8.77 \pm 5.22$ & $2.900-25.50$ & $2.60-24.90$ \\
\hline Cortisol (mcg/dL) & $9.87 \pm 4.21$ & $4.1-21.80$ & $5-25$ \\
\hline
\end{tabular}

Table 3. Odds ratio of presence of metabolic syndrome according to the duration of smoking

\begin{tabular}{lccc}
\hline Duration of smoking & MS $(\mathrm{n})$ & OR & $P$ \\
\hline $0-20$ years & 1 & 1.00 & \\
21-30 years & 3 & 3.30 & 0.016 \\
$>30$ years & 7 & 9.63 & \\
\hline
\end{tabular}

Table 4. Association between anthropometric, biochemical and nutritional parameters at the beginning of treatment for smoking cessation

\begin{tabular}{lcc}
\hline \multicolumn{3}{l}{ Association between BMI and anthropometric and biochemical parameters } \\
\hline Variables & $\mathrm{r}$ & $\mathrm{p}$ \\
\hline WC & 0.90 & 0.0001 \\
\%BF & 0.79 & 0.0001 \\
Glycemia & 0.42 & 0.04 \\
TG & 0.47 & 0.002 \\
CI & 0.65 & 0.0001 \\
\hline Association between IC and anthropometric and biochemical parameters & \\
\hline Variables & $\mathrm{r}$ & $\mathrm{p}$ \\
\hline WC & 0.86 & 0.004 \\
Glycemia & 0.55 & 0.007 \\
TG & 0.54 & 0.008 \\
\%BF & 0.43 & 0.004 \\
\hline Association between insulinaemia and anthropometric parameters & \\
\hline Variables & $\mathrm{r}$ & $\mathrm{p}$ \\
\hline WC & 0.74 & 0.001 \\
Cl & 0.60 & 0.001 \\
\hline
\end{tabular}




\section{DISCUSSION}

The results of this study indicate that smokers at initiation of treatment had increased risk for developing chronic diseases such as cardiovascular disease, type 2 DM and MS, since most of these individuals have changes in lipid profile, increase fasting glucose and blood pressure and overweight and obesity abdominal. It was also found that smokers with longer smoking had higher odds of developing MS.

The WHO considers smoking as a disease in expansion, with a mean age of initiation of 15 years $^{27}$. The present study corroborates this finding, since the average age of smoking initiation was found to be $16.35 \pm 4.72$ years. In study conducted by Prigol et al. ${ }^{5}$, the degree of nicotine dependence was directly related to the age of onset of smoking, and the individuals who started smoking before age 20 were classified with high nicotine dependence, factor related with increased risk of coronary heart disease.

The degree of nicotine dependence, assessed by the FTND was high in more than half of the volunteers. However, no correlation was found between this variable with none of the other variables. Some studies have reported a correlation between the number of cigarettes smoked and alteration in lipid profile or even on other risk factors associated with MS, such as abdominal obesity, increased blood pressure and increased fasting glucose ${ }^{5,28-30}$. In the present study, this observation was not found. This finding may be explained by the fact that it occurred an evaluation point and not monitoring the number of cigarettes smoked over the years. However, a positive association was observed between the presence of MS and the duration of smoking, which revealed that individuals who smoke for more than 30 years, possessed 9.6 times greater risk of developing MS ( $p=0.016)$.

Studies suggest that nicotine promotes increased energy expenditure and reduces appetite, which explains why smokers having a lower BMI than nonsmokers, and the common weight gain after smoking cessation 12,31,32. In contrast, it is observed that heavy smokers ( $>40$ cigarettes/day) tend to have higher body weight than light smokers $(<20$ cigarettes/day). Suggests that heavy smokers are more likely to adopt behaviors that favor weight gain, such as low physical activity, low intake of fruits and vegetables and high intake of alcohol ${ }^{12}$. Besides being overweight, these behaviors also contribute to the appearance of other cardiovascular risk factors such as increased WC, changes in BP and changes in lipid and glycemic profiles. In this study there was no correlation between the number of cigarettes smoked per day and BMI. However, it should be emphasized again the need for an assessment of the number of cigarettes smoked normally, since it was observed that, when selected for treatment, some individuals have reduced the number of cigarettes smoked per day.
It is very common to use anthropometric indices to classify individuals as to the risk of development of chronic degenerative diseases. In addition to BMI, another index that has been used is the $\mathrm{IC}$, an indicator of abdominal obesity able to assess the presence of high cardiovascular risk. According Pitanga and Lessa ${ }^{22}$ the IC can be considered the best indicator of high cardiovascular risk when compared to WC and BMI, described as intermediate and low discriminatory power of high cardiovascular risk, respectively. In this study, more than half (52.1\%) of smokers had elevated cardiovascular risk according to the IC.

BMI showed good association with visceral adiposity, $\% \mathrm{BF}$, and alterations of plasma glucose and triglycerides. According to Bray and Bellanger ${ }^{33}$, obesity is a major risk factor for cardiovascular disease, diabetes and dyslipidemia, the latter being characterized by elevated serum TG and low serum concentrations of HDL-C. BMI was also associated with IC, indicating a positive correlation between increased body mass and increased cardiovascular risk.

In addition to BMI, the IC was correlated with insulin, glucose, triglycerides and the \%BF. Why be an indicator of abdominal obesity, it is expected that this index shows a positive correlation with these variables. Moreover, visceral adipose tissue increases the plasma concentrations of free fatty acids in plasma, and these increase hepatic glucose production, inhibit insulin action in the liver $^{28}$ and increase the production of very low density lipoprotein $(V L D L)^{13}$. Studies indicate increased levels of blood pressure in smokers compared with nonsmokers ${ }^{28,34}$. In this study, the prevalence of change in blood pressure was $30.4 \%$. In cross-sectional study by Nakashita et al. ${ }^{29}$, the prevalence of hypertension in light smokers ( $<20$ cigarettes/day) was $51 \%$.

Of all patients, over $90 \%$ had some type of alteration lipid profile, being common association between increased plasma levels of LDL-C and decreased HDL-C (52\%). These changes are usually associated with increased sympathetic activity caused by nicotine ${ }^{28}$ and represent a future risk for the onset of atherosclerosis, being more significant in chronic smokers ${ }^{5}$. The abdominal obesity shown in smokers may also contribute to the increased incidence of dyslipidemia, since the increase in visceral adiposity is associated with increased plasma lipoprotein ${ }^{9,35}$. Thus, the high percentage of abdominal obesity found may be related to changes observed in the lipid profile.

Regarding glucose, it was observed that although the mean values were within the normal range, about a third (30.4\%) patients had blood glucose greater than or equal to $100 \mathrm{mg} / \mathrm{dL}$. Nakashita et al. ${ }^{29}$ in cross-sectional study with Japanese subjects, found a prevalence of $5.1 \%$ in cigarette smokers. Studies indicate that tobacco use has been associated with reduced insulin sensitivity and development of in- 
sulin resistance ${ }^{28}$, promoting glucose metabolism disorders, leading to hyperglycemia ${ }^{14}$.

Serum concentrations of the hormones insulin and cortisol were increased in only one smoker. Chiolero et al.12 reported that in healthy men, chronic smoking is associated with increased insulin levels, independent of other factors known to influence the sensitivity to this hormone. Although serum cortisol did not increase in most patients evaluated in this study, other authors have shown that smoking increases circulating levels of this hormone and others such as catecholamines, and growth hormone actions that are antagonistic to insulin and may contribute to insulin resistance and higher blood glucose levels between smokers ${ }^{28,36}$. Excess abdominal fat may also explain the occurrence of IR, since the present study showed a correlation between insulinemia and WC.

There is evidence that smoking leads to an increase in visceral fat mass, which is influenced by the concentration of cortisol ${ }^{12,28,29}$. One of the characteristics of this hormone is increased lipogenesis in visceral adipose tissue ${ }^{13}$. Other studies have shown increased levels of this hormone in smokers, especially in the first hour after smoking ${ }^{10,11}$. Although the analysis of these hormones have been performed in the morning (fasting), a limiting factor for the result was the lack of standardization between the time of the last cigarette and examination.

The main limitation of this study was to have a cross-sectional design and evaluation of one group of smokers, which affects the interpretation of results, since the small sample of patients and absence of a temporal sequence that prevents establish causal links between exposure and disease development factor. Moreover, the absence of a control group was a factor that prevented comparisons were made with data from healthy individuals of the same sex and age. However, the study will be continued to compare the changes that were observed at the beginning with the changes at the end of treatment. For this analysis there is no need for a control group. However, the study was positive in indicating the urgency of smoking cessation, confirming the harmful effects of tobacco on the health of these individuals, and indicates the need for multidisciplinary team in the treatment of smokers.

In conclusion, the smokers evaluated at the beginning of treatment for smoking cessation have changes in lipid profile, increased fasting glucose, increased blood pressure, overweight and abdominal obesity, which may contribute to the development of chronic diseases, particularly cardiovascular diseases, type 2 DM and MS. Regardless of the number of cigarettes smoked per day, the profile of smokers had evaluated increased risk for developing MS, especially those with longer duration of smoking. Smokers require urgently for smoking cessation, to prevent metabolic complications associated with tobacco use. These results reinforce the importance of the multidisciplinary team involved in treatment strategy, aimed not only smoking cessation as well as prevention of diseases associated with smoking and improving the quality of life.

\section{INDIVIDUAL CONTRIBUTIONS}

Gláucia Renata Souza Rodrigues - Contributed to data collection, interpretation of the data and also contributed to drafting the article, revising it critically and approval of the final version to be published.

Marcela Melquíades - Contributed to data collection, interpretation of the data and also contributed to drafting the article, revising it critically and approval of the final version to be published.

Maria Alvim Leite - Contributed to data collection, literature review, interpretation of the data and also contributed to drafting the article, revising it critically and approval of the final version to be published.

Maíra Barros Louro - Contributed to data collection, literature review, interpretation of the data and also contributed to drafting the article, revising it critically and approval of the final version to be published.

Carmen Perches - Contributed to biochemical analysis, interpretation of the data and also contributed to drafting the article, revising it critically and approval of the final version to be published.

Ana Lúcia de Almeida Vargas - Participated in the project design contributed to conception, interpretation of results, drafting of article, approval of final version to be published.

Sheila Cristina Potente Dutra Luquetti - Participated in the project design contributed to conception, interpretation of results, drafting of article, approval of final version to be published.

Aline Silva de Aguiar Nemer - Participated in the project design contributed to conception, interpretation of results, drafting of article, approval of final version to be published.

\section{DECLARATION OF INTERESTS}

None declared.

\section{ACKNOWLEDGMENTS}

The authors thanks to Residência Multiprofissional em Saúde do Adulto (HU/UFJF).

This research was supported by National Council for Scientific and Technological Development (Conselho Nacional de Desenvolvimento Científico e Tecnológico - CNPq - Process 471642/2011-8), PROEX/UFJF and PROPESQ-BIC/UFJF. Lu- 
quetti SCD thanks to Coordination for the Enhancement of Higher Education Personnel (Coordenação de Aperfeiçoamento de Pessoal de Nível Superior - Capes) and State of Minas Gerais Research Foundation (Fundação de Amparo à Pesquisa do Estado de Minas Gerais - Fapemig).

\section{REFERENCES}

1. WHO. World Health Organization. WHO report on the global tobacco epidemic, 2011: warning about the dangers of tobacco. Geneva: WHO, 2011. Available from: http:// whqlibdoc.who.int/publications/2011/9789240687813_eng.pdf

2. WHO. World Health Organization. The tobacco industry documents. What they are, what they tell us, and how to search them. A practical manual. Washington DC: WHO, 2002. Available from: www.who.int/tobacco/communications/TI_manual_content.pdf

3. Vigitel Brasil 2011: Vigilância de fatores de risco e proteção para doenças crônicas por inquérito telefônico. Ministério da Saúde, Secretaria de Vigilância em Saúde - Brasília: Ministério da Saúde; 2012. Available from: http://portalsaude.saude.gov.br/portalsaude/ arquivos/pdf/2012/Ago/22/vigitel_2011_final_0812.pdf

4. Rosemberg J. Pandemia do Tabagismo - Enfoques Históricos e Atuais. São Paulo: Secretaria Estadual de Saúde; 2002.

5. Prigol M, Marmentini F, Grazziotin NA, Macedo SMD. Efeito do tabagismo sobre o perfil lipídico e suas implicações em detentos internos do Presídio Estadual de Erechim-RS. Rev Bras Anal Clin. 2007;39(1):3-8.

6. Wilsgaard T, Jacobsen BK. Lifestyle factors and incident metabolic syndrome. The Tromsø Study 1979-2001. Diabetes Res Clin Pract. 2007;78:217-24.

7. Ishizaka N, Ishizaka Y, Toda E, Hashimoto H, Nagai R, Yamakado M. Association between cigarette smoking, metabolic syndrome, and carotid arteriosclerosis in Japanese individuals. Atherosclerosis. 2005;181:381-8.

8. International Diabetes Federation - IDF. The IDF consensus worldwide definition of the Metabolic Syndrome, 2006. Available from: http://www.idf.org/webdata/docs/IDF_ Meta_def_final.pdf

9. Rosini N, Rosini AD, Mousse DM, Rosini GD. Prevalência de síndrome metabólica e estratificação de risco para DAC em pacientes hipertensos-tabagistas. Rev Bras Anal Clin. 2007;39(3):223-6

10. Xue Y, Morris M, Ni L, Guthrie SK, Zubieta JK, Gonzalez K, et al. Venous plasma nicotine correlates of hormonal effects of tobacco smoking. Pharmacol Biochem Behav. 2010:95(2):209-15

11. Mello NK. Hormones, nicotine, and cocaine: clinical studies. Horm Behav. 2010;58:57-71.

12. Chiolero A, Faeh D, Paccaud F, Cornuz J. Consequences of smoking for body weight, body fat distribution, and insulin resistance. Am J Clin Nutr. 2008;87:801-9.

13. Suplicy HL. Obesidade visceral. Resistência à insulina e hipertensão arterial. Rev Bras Hipertens. 2000;2:136-41.

14. Xie XT, Liu Q, Wu J, Wakui M. Impact of cigarette smoking in type 2 diabetes development. Minireview Acta Pharmacol Sin. 2009:30(6):784-7.

15. Heartherton TF, Kozlowski LT, Frecker RC, Fagerström KO. The Fargerstrom Test for Nicotine Dependence: a revision of the Fagerström Tolerance Questionnaire. Br J Addict. 1991;86:1119-27.
16. Halty $L S$, Hüttner MD, Netto ICO, Santos VA, Martins G. Análise da utilização do Questionário de Tolerância de Fagerström (QTF) como instrumento de medida da dependência nicotínica. J Bras Pneumol. 2002;28(4):180-6.

17. World Health Organization. Obesity: preventing and managing the global epidemic. Report of a WHO Consultation. Geneva, World Health Organization; 1998. Technical Report Series, 894.

18. Lipschitz DA. Screening for nutritional status in the elderly. Primary Care. 1994;21(1):5567.

19. Black D, James WPT, Besser GM, Brook CGD, Craddock D, Garrow JS, et al. Obesity. A report of the Royal College of Physicians. Clin Med. 1983;17:5-65.

20. Lohman TG. Advances in body composition assessment. Champaign, Human Kinetics Publishers, Champaign, II. 1992; 150 pages, Monograph. Available from: http://pen. sagepub.com/content/18/3/283.1.extract

21. Valdez R, Seidell JC, Ahn Yl, Weiss KM. A new index of abdominal adiposity as an indicator of risk for cardiovascular disease. A cross-population study. Int J Obes Relat Metab Disord. 1993; 17(2):77-82.

22. Pitanga FJG, Lessa I. Indicadores antropométricos de obesidade como instrumento e triagem para risco coronariano elevado em adultos na cidade de Salvador-Bahia. Arq Bras Cardiol. 2005;85(1):26-31.

23. Salgado ALFA, Carvalho L, Oliveira AC, Santo VN, Vieira JG, Parise ER. Insulin Resistence Index (HOMA-IR) in the differentiation of patients with non-alcoholic fatty liver disease and healthy individuals. Arq Gastroenterol. 2010;47(2):165-9.

24. Sociedade Brasileira de Diabetes. Diretrizes (SBD). São Paulo 2009 [Internet]. Available from: http://www.diabetes.org.br/attachments/diretrizes09_final.pdf

25. Expert Panel on Detection, Evaluation, and Treatment of High Blood Cholesterol in Adults (Adult Treatment Panel III). Executive Summary of the Third Report of the National Cholesterol Education Program (NCEP). JAMA. 2001;285(19),2486-97.

26. Alberti KG, Zimmet P, Shaw J. IDF Epidemiology Task Force Consensus Group: the metabolic syndrome - A new worldwide definition. Lancet. 2005;366:1059-62.

27. WHO. World Health Organization. Tobacco \& the Rights of the Child, 2001: Available from: http://whqlibdoc.who.int/hq/2001/WHO_NMH_TFI_01.3_Rev.1.pdf

28. Balhara YPS. Tabacco and metabolic syndrome. Indian J Endocrinol Metab. 2012;16(1):81-7.

29. Nakashita Y, Nakamura M, Kitamura A, Kiyama M, Ishikawa Y, Mikami H. Relationships of cigarette smoking and alcohol consumption to metabolic syndrome in Japanese men. J Epidemiol. 2010;20:391-7.

30. Nakanishi N, Takatorige T, Suzuki K. Cigarette smoking and the risk of the metabolic syndrome in middle-aged Japanese male office workers. Indust Health. 2005;43:295-301.

31. Mineur YS, Abizaid A, Rao Y, Salas R, DiLeone RJ, Gündisch D, et al. Nicotine decreases food intake through activation of POMC neurons. Science. 2011;332(6035):1330-2.

32. Chatkin $R$, Chatkin JM. Tabagismo e variação ponderal: a fisiopatologia e genética podem explicar esta associação. J Bras Pneumol. 2007;33(6):712-9.

33. Bray GA, Bellanger T. Epidemiology, trends, and morbidities of obesity and the metabolic syndrome. Endocrine. 2006;29(1):109-17.

34. Primatesta P, Flaschetti E, Gupta S, Marmot MG, Poulter NR. Association between smoking and blood pressure: evidence from the Health Survey for England. Hypertension. 2001;37:187-93.

35. Lima WA, Glaner MF. Principais fatores de risco relacionados às doenças cardiovasculares. Artigo de revisão. Rev Bras Cineantropom Desempenho Hum. 2006;8(1):96-104.

36. Frati AC, Iniestra F, Ariza CR. Acute effect of cigarette smoking on glucose tolerance and other cardiovascular risk factors. Diabetes Care. 1996;19:112-8. 